\title{
PRECIOS, PRODUCTO AGRARIO Y NIVELES DE VIDA EN LAS FRONTERAS RIOPLATENSES, 1700-1810: UNA NUEVA MIRADA SOBRE EL CRECIMIENTO ECONÓMICO TARDOCOLONIAL*
}

\author{
JULIO DJENDEREDJIAN \\ Instituto Ravignani, Universidad de Buenos Aires/CONICET ${ }^{\mathrm{a}}$ \\ JUAN LUIS MARTIRÉN \\ Instituto Ravignani, Universidad de Buenos Aires/CONICET ${ }^{\mathrm{a}}$
}

Prices, Agrarian Output and Living Standards in the River Plate Borders, 1700\1810: A New Look into Economic Growth in the Late Colonial Era

\begin{abstract}
This article presents and analyses wholesale price series of Santa Fe (Argentina), an essential core of colonial commercial circuits, during the period 1700-1810. Mainly from monastic sources, the presented series include 14 products from local and regional origin. Production data has also been deflated using these indexes and purchasing power of wages has been measured. This allows studying inflation, deflation and standards of living and their relation to economic growth. Growth, even prior to trade liberalization of 1778, was matched by deflation so it may suggest improvements in mercantile circuits. This new evidence provides a solid tool for regional and international comparative analysis.
\end{abstract}

Keywords: prices, agrarian production, standards of living, colonial río de la plata

JEL Code: E31, N36, N56

* Received 15 September 2014. Accepted 2 January 2015. Los autores desean agradecer los valiosos comentarios y sugerencias de Rodolfo Frank, Pablo Gerchunoff, Rafael Dobado, Martín Cuesta y otros colegas a versiones previas de este artículo, así como a los evaluadores anónimos. Los fondos para esta investigación han sido provistos por el Consejo Nacional de Investigaciones Científicas y Técnicas (CONICET) de Argentina.

a 25 de Mayo 221, $2^{\circ}$ piso (C1002ABE) Ciudad de Buenos Aires, Argentina. juliodjend@yahoo. com.ar; jlmartiren@hotmail.com 


\section{RESUMEN}

El artículo presenta y analiza series de precios mayoristas de la ciudad de Santa Fe (Argentina) para 1700-1810, elaboradas sobre la base de fuentes conventuales. Los índices obtenidos incluyen catorce productos, de origen local y regional. Han servido además para deflactar índices de producción y evaluar el poder de compra del salario. Se busca así estudiar los ciclos de inflación y deflación, y su relación con el crecimiento económico. El período elegido abarca diferentes coyunturas que afectaron la evolución de los precios y la oferta de bienes, mostrando un crecimiento con deflación antes de la apertura atlántica de 1778, lo que podría indicar mejoras cualitativas en los circuitos mercantiles. Esta nueva evidencia ofrece así un sólido punto de comparación regional e internacional.

Palabras clave: Precios, Producción agraria, Niveles de vida, Río de la Plata colonial

\section{INTRODUCCIÓN}

El actual auge de los estudios sobre el nivel de vida presta renovado interés a las series de precios de bienes de uso y consumo. La acumulación de estudios de caso impone nuevos ritmos a la comparación regional e internacional, proponiéndose series sintéticas, disponibles universalmente; pero, al mismo tiempo, cercanas al gasto diario de la población y sensibles a los cambios en las pautas de consumo a través del tiempo. Serán, así, más certeras que las antiguas series de materias primas e insumos al por mayor, o que las canastas fijas ligadas a amplios y complejos conjuntos de datos que, por desgracia, parece que sólo en algunos casos pueden obtenerse. Además, las comparaciones internacionales resultarán más útiles ${ }^{1}$.

Faltos de gran parte de la información disponible para épocas posteriores, los tiempos preestadísticos a menudo nos ofrecen sólo escasas variables para estudiar el movimiento económico; entre ellas, las series de precios ocupan un lugar imprescindible, y no es casualidad que la literatura respectiva sea muy sólida. Gracias a la misma ha ido cambiando últimamente nuestra

1 En los últimos años, los estudios sobre precios y salarios en distintos espacios de América Latina entre los siglos XVIII y XIX han cobrado gran relevancia en la historiografía económica internacional (Arroyo Abad et al., 2012; Allen et al., 2012). A su vez, el uso y la elaboración de series de precios de «tercera generación» ha sido propuesto recientemente por Dobado y García (2014) y González Mariscal (2013, pp. 80-83), quienes criticaron las limitaciones de los índices de «segunda generación». Las variaciones de las materias primas no necesariamente son correlativas y proporcionales a las de los precios de los bienes de consumo, como nos lo recuerda Nordhaus (1996, pp. 55-65). Sobre el tema puede verse también el estudio de Hoffman, Jacks, Levin y Lindert (2002). 
comprensión del funcionamiento de los mercados y aun de la economía misma en tiempos de ancien régime; multitud de aspectos clave, como los patrones de crecimiento, la irrupción de nuevos productos a partir de la extensión del contacto intercontinental o las consecuencias sociales de las alteraciones en los niveles relativos de los precios, dan nuevos alicientes al esfuerzo adicional que significa construir series para siglos pasados (reflexiones útiles al respecto en de Vries, 1993, pp. 85-100). El tradicional interés en series para núcleos de importancia económica o política (en esencia, las ciudades de mayor dimensión) ha ido dejando paso también al convencimiento de que es necesario contar con más y mejor información sobre la evolución del costo de bienes y servicios en ciudades menores o en ámbitos rurales (donde, valga recordarlo, residía y producía la mayor parte de la población antes del siglo XX) como único camino para medir y estudiar con alguna certeza los hechos económicos que afectaron al conjunto, y comprender en forma menos impresionista el funcionamiento de los mercados de entonces. Por otro lado, la elaboración de análisis comparados, siempre aleatoria y difícil, lo es mucho más para tiempos anteriores a la gran globalización del siglo XIX, resintiéndose a menudo no sólo de la falta de evidencia de calidad sino, sobre todo, por nuestro conocimiento desigual sobre patrones de consumo y sus cambios, ya sea a lo largo del tiempo o del espacio. Razones culturales, ambientales y no sólo económicas implicaban que el acceso a ciertos bienes fuera imprescindible para algunos y en determinados sitios, y no lo fuera para otros. De modo que no sólo es necesario cubrir con más sustancia empírica una multitud de aspectos clave de la economía de los últimos siglos, sino responder nuevas preguntas a partir de la comparación de los resultados de distintas series de datos (Allen et al., 2005; Van Zanden, 1999 y 2005; Llopis y García, 2007; Özmucur y Pamuk, 2002; Malanima, 2006; Broadberry y Gupta, 2005).

En lo que respecta a América Latina, los estudios han vuelto a poner de relieve el debate sobre el «retraso» relativo en el crecimiento económico experimentado por la región desde el siglo XIX y sobre las condiciones de vida comparadas con otras partes del mundo ${ }^{2}$. La evidencia, tanto desde el poder de compra de los salarios como desde la antropometría, muestra, al menos hasta inicios de esa centuria, un horizonte bastante favorable para el área, al menos en la comparación en torno a ciertos indicadores básicos (una aproximación reciente al respecto en Dobado y García, 2014). A ello debe agregarse que, en el caso particular de algunas regiones de frontera, el nuevo esquema de relación con el mundo luego de la Independencia parece haber impactado favorablemente, generando una desigualdad creciente con respecto a áreas antaño nucleares del imperio, tanto en bienestar relativo como en la dinámica del crecimiento. Esto obliga a repensar los atributos de las instituciones económicas con las que contaba la América Latina colonial

2 El tema tiene viejas raíces; véase, por ejemplo, Haber (1998, pp. 2-5), Coatsworth (1990, pp. 80-161 y 1998, pp. 23-54); también Prados de la Escosura (2004). 
y el papel de éstas como obstáculos o favorecedoras del crecimiento y la desigualdad ${ }^{3}$. En efecto, en esas áreas de frontera, la «reversión de fortunas» de inicios del siglo XIX parece haber comenzado a manifestarse ya en las postrimerías del régimen colonial, lo cual abre incógnitas, entre otras cosas, sobre la eficiencia de sus mercados interiores a la hora de generar respuestas al cambio de paradigma y a la forma de gestión de los recursos, ya que su mera abundancia no explicaría plenamente esa nueva dinámica.

En ese esquema adquiere importancia el caso que trataremos aquí. En lo esencial, aún desconocemos los detalles de la larga transición del siglo XVIII, el proceso por el cual el Río de la Plata de la conquista tardía, todavía marcado por claras diferencias de casta, abundantes recursos mostrencos y un cerco indígena capaz de hacer retroceder peligrosamente el área bajo dominio hispano, terminó transformándose en una sociedad mestiza que se expandía sobre sus fronteras, avanzaba resueltamente hacia la integración mercantil atlántica y en la que las jerarquías, aun cuando nunca dejaran de estar presentes, perdían terreno ante factores más prosaicos de diferenciación social, como el éxito en los negocios ${ }^{4}$. Aquella economía de finales del Siglo de Hierro, en la que las transacciones se pautaban todavía en "pesos de la tierra» pagaderos en géneros y en la que los cabildos se esforzaban por establecer precios justos en épocas de carestía, aquella que una centuria más tarde se había despedido de las antiguas tradiciones de control estamental de la producción y estaba a punto de integrarse en el ritmo avasallador de los mercados internacionales pautados por la Revolución Industrial, comenzaba a construir sus primeras plantas manufactureras y a diversificar, cada vez con mayor amplitud, las pautas del consumo urbano y rural, con un creciente acceso a bienes internacionalmente transables, como lo atestiguan los estudios disponibles sobre inventarios de tiendas ${ }^{5}$. Ese crecimiento, en un contexto tecnológico tradicional, nos es aún esquivo en lo que respecta a sus ciclos, a sus puntos de ruptura y expansión, por lo que se tiende a identificarlo meramente con el desarrollo de la demanda atlántica; aunque esto fuera cierto, debería haber impactado en los niveles de vida relativos de la

${ }^{3}$ La existencia de instituciones favorables a la ampliación de la propiedad privada (contra aquellas que perpetuaban el dominio extractivo en beneficio de élites pequeñas) ha sido señalada como uno de los factores principales de una evolución exitosa en las antiguas colonias europeas luego del inicio del siglo XIX. Acemoglu, Johnson y Robinson (2002).

4 La copiosa producción historiográfica reciente sobre la economía rioplatense virreinal no se ha visto aún replicada del todo para el período anterior; pero, de todas maneras, la abundancia de estudios existentes (y, quizá, sobre todo, los elaborados sin centrarse necesariamente en la economía) muestran esos contrastes a los que hacemos referencia. Véase, por ejemplo, el análisis de la organización política del territorio como factor de acceso y uso de los recursos en los siglos XVI y XVII en Barriera (2013, pp. 211-25.), y el efectuado por Moutoukias (2000), dando cuenta resumida de los cambios habidos en el Río de la Plata entre esos años y el final del período borbónico. Un interesante estudio sobre el surgimiento de una sociedad mestiza en el Paraguay de la segunda mitad del siglo XVIII en Telesca (2009). Un excelente retrato de esa economía poscolonial en Míguez (2008).

5 Véase, por ejemplo, Mayo (dir.) (2000) y Djenderedjian (2006, pp. 287-300). 
población local. Así, conocer más en profundidad ese proceso implica la necesidad de contar con datos de primera mano sobre sus activos; y, entre éstos, los precios de los bienes de consumo y los servicios, así como los salarios, son sin duda fundamentales ${ }^{6}$.

Entonces, con el fin de medir y comprender mejor el crecimiento económico rioplatense y los cambios en el nivel de vida durante el largo siglo XVIII, en el presente trabajo presentaremos y analizaremos series de precios mayoristas de la ciudad de Santa Fe, situada en el interior de la actual Argentina, para los años $1700-1810^{7}$. Nos valdremos asimismo de esas series para deflactar índices de producción y para evaluar el poder de compra del salario, considerando éste como una parte de los ingresos familiares, de importancia muy cambiante, pero en todo caso un indicativo aproximado del valor del trabajo ofrecido en el mercado. Las series comienzan con los primeros datos disponibles y culminan en el momento en que, por la apertura atlántica a todas las banderas y los efectos disruptivos de las guerras de independencia, se producirán alteraciones sustanciales en el recorrido de los precios y en la oferta de bienes. Por eso decidimos extender el período sólo hasta 1810, aun cuando existen datos para años posteriores ${ }^{8}$. Los índices

${ }^{6}$ Entre las diversas deficiencias actuales de la historia económica rioplatense, una de la más acuciante gira en torno a la falta de series útiles de precios de bienes y factores. El período anterior a 1900 es, en Argentina, especialmente crítico. Si bien contamos con diversas series de precios, algunas de ellas de buena calidad, las mismas a menudo poseen en el largo plazo grandes claros que dificultan la comprensión de los procesos económicos; otras, en cambio, no son en realidad útiles en tanto que series: se trata, en general, de trabajos más débiles o no sistemáticos, con diversas fallas, entre otras la falta de especificación de los criterios de selección de los datos. Un ejemplo al respecto en Barba (1999). Por otro lado, sólo se ha cubierto un haz reducido de bienes y servicios, y en especial para tres ciudades: Buenos Aires, con Álvarez (1929), Broide (1951), Gorostegui (19621963), Cortés Conde (1979), Johnson (1990), Garavaglia (1995), Banzato (2005) y Cuesta (2009); Córdoba, con Novara y Palmieri (1968), Arcondo (1992) y Tognetti (2008), entre otros; y Santa Fe, con Djenderedjian y Martirén (2013). Cabe mencionar, asimismo, los estudios de Tandeter y Johnson (1992) para Potosí. Pero una parte de lo existente se compone de series de precios de primera generación, de alcance geográfico limitado, no homogéneas, de plazo corto, parcialmente incompletas y entre las cuales no siempre hay empalme.

7 Se ha debatido largamente la utilidad de diversas fuentes para la historia de precios; básicamente entre partidarios de mercuriales (a partir de la metodología de Labrousse) y de registros contables de instituciones religiosas y hospitales, siguiendo los trabajos de Hamilton. Los registros conventuales, aun cuando hayan sido criticados por constituir fuentes de comunidades que pueden no reflejar las pautas de consumo de un amplio sector de la población, y siempre que se haga un trabajo de análisis crítico suficiente, suelen proveer datos de precios de bienes que sí son masivamente consumidos, y, en tanto esos bienes hayan sido adquiridos en el mercado, resultan un indicio útil del movimiento de sus precios, en especial en el largo plazo. En América Latina, justamente los libros de cuentas de instituciones religiosas son, muy a menudo, las únicas fuentes disponibles para períodos alejados del presente, de modo que se han utilizado mucho en varios estudios. Además de los ya citados para Buenos Aires, Santa Fe y Córdoba, existen otros estudios que han utilizado fuentes eclesiásticas para la América colonial, tales como los de Larraín Melo (1980), Johnson (1973), Mattoso (1973), Torres (2013), Brown (1992) y Tandeter y Wachtel (1992). Una interesante crítica de estas fuentes en Alves Carrara (2008).

${ }^{8}$ En efecto, después de 1810 cambian notablemente muchas cosas. Entre otras, pierden importancia o directamente desaparecen las antiguas medidas coloniales (por ejemplo, el vino 
elaborados presentan, entendemos que por primera vez, el recorrido completo, durante más de un siglo, de un espectro bastante amplio de los precios mayoristas de una ciudad del área rioplatense, ofreciendo por tanto un punto de comparación regional e internacional mucho más sólido que el existente hasta el momento.

\section{SANTA FE EN EL SIGLO XVIII: RETRATO DE UN ENCLAVE ESTRATÉGICO PARA EL COMERCIO COLONIAL}

Fundada en 1573, la ciudad de Santa Fe se pensó como un puerto intermedio para el tránsito fluvial desde Buenos Aires o el interior hacia el Paraguay y viceversa. Desde 1662, la ciudad fue puerto preciso, lo que obligaba a todos los navíos mercantes a detenerse allí y pagar impuestos (Cervera, 1907; Barriera, 2006; Suárez y Tornay, 2003). Esto la consolidó como un centro de importancia estratégica dentro del comercio colonial; la ventaja que otorgaba el control de la principal vía fluvial del espacio rioplatense, así como su carácter de punto intermedio en las rutas terrestres, permitió el desarrollo de nuevos curatos poblados por labradores, pastores y grandes establecimientos ganaderos (Suárez y Tornay, 2003, pp. 523 y ss.).

El plano precedente permite apreciar las ventajas de que gozaba Santa Fe como núcleo mercantil y el valor de su posición. Durante casi todo el siglo XVIII, por su puerto pasaban, y pagaban impuestos, todos los cargamentos declarados de yerba y textiles que venían de Misiones Guaraníes y se dirigían hacia Buenos Aires, las provincias cuyanas, Santiago de Chile, el norte de la actual Argentina, el Alto Perú e incluso el Cuzco. En sentido inverso, todo lo que se dirigía hacia el Paraguay, aun los productos ultramarinos de Buenos Aires, debía registrarse en Santa Fe antes de remontar el río Paraná. Estas ventajas comerciales, sumadas a su destacada producción ganadera de mulas para el Alto Perú y cueros vacunos para el mercado atlántico, eran las bases de su importancia económica.

Hay que destacar, no obstante, que en 1780 se anularía la condición de puerto preciso ${ }^{9}$, lo que sumado a las rebeliones indígenas altoperuanas de inicios de la década de 1780 y a la competencia de la ganadería vacuna que rápidamente se desarrollaba en la cercana Entre Ríos (con mejores tierras y

\footnotetext{
(footnote continued)

vendido en botijas pasa a venderse en barriles; la harina, antes transada en arrobas, pasa a cotizarse en barricas o en quintales). Aparecen productos nuevos, como los fideos; y las antiguas telas bastas de Misiones o del Alto Perú son reemplazadas por textiles industriales. Está de más decir que no hay duda de que, antes de 1810, ya circulaban por el área algunos de esos productos; pero, al menos en las cuentas que analizaremos, al principio no estaban y luego sí.

${ }^{9}$ Las quejas sobre el mismo llegaban con frecuencia al Cabildo de Buenos Aires; véase, por ejemplo, el acuerdo del 5 de noviembre de 1755, en Acuerdos del Cabildo de Buenos Aires, libro XXX, t. I, 3. ${ }^{\text {a }}$ serie, p. 565. También Barriera (2006, pp. 169 y ss.).
} 
IMAGEN 1

SANTA FE COMO ENCLAVE ESTRATÉGICO DEL COMERCIO COLONIAL

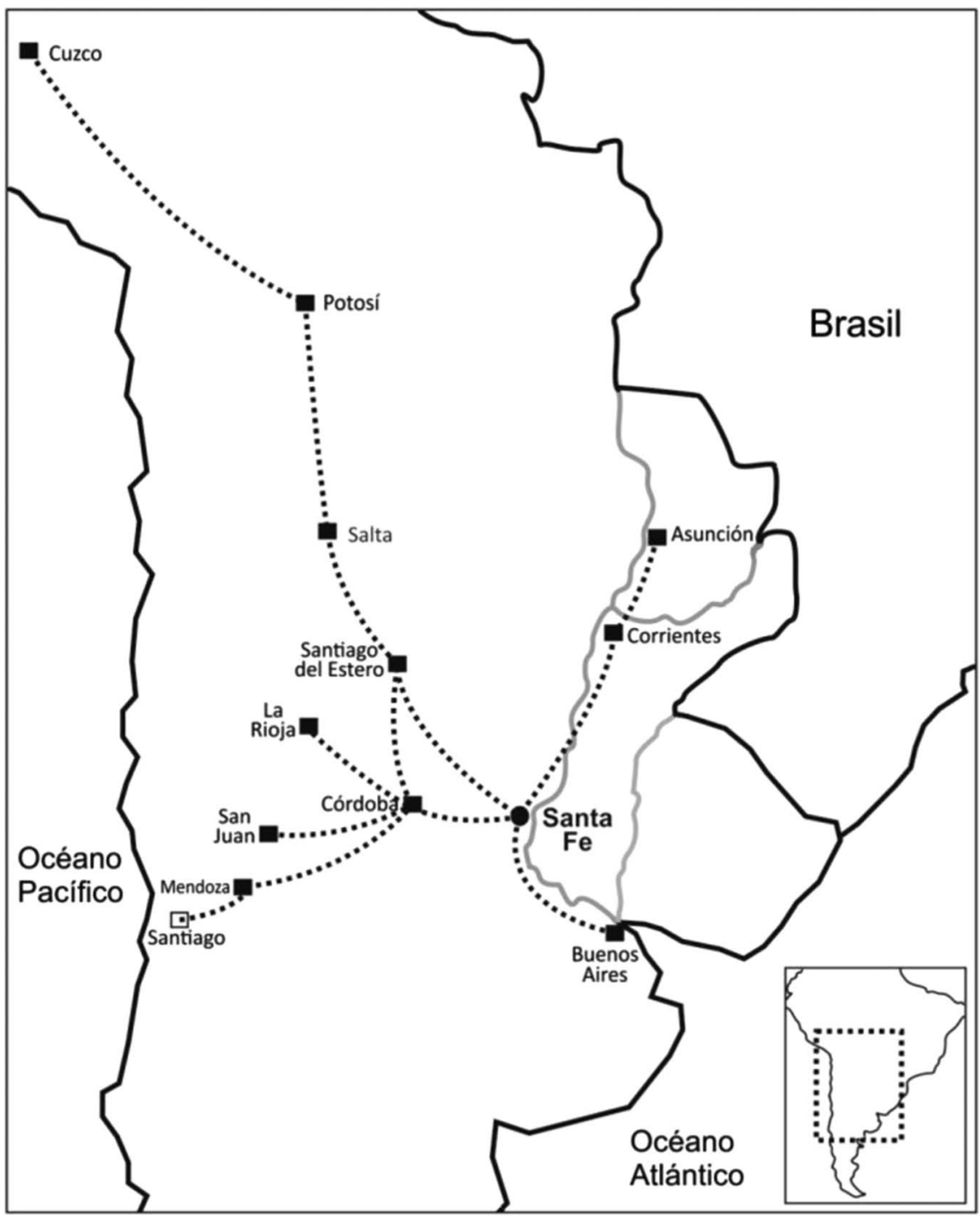

Fuente: elaborado a partir de datos extraídos de los registros de alcabalas de la ciudad de Santa Fe durante el siglo XVIII (en AGPSF, Contaduría, tt. 9-13). 
menores costos de transporte hasta el Atlántico) habría de causar dificultades a la economía santafesina. Aunque, pese a todo, también a comienzos del siglo XIX, la estratégica posición de la ciudad y su campaña le permitirían conservar un puesto de preeminencia; y a sus hacendados y comerciantes, acumular bienes materiales, así como rentas considerables al fisco (Halperín Donghi, 1979, p. 31; Tarragó, 1995-1996) ${ }^{10}$.

No contamos con censos poblacionales de Santa Fe anteriores a 1858, y sólo existen datos estimativos para 1755,1760 y $1794^{11}$. Los registros parroquiales son bastante deficientes para el siglo XVII, y sólo adquieren algo de regularidad y confiabilidad a partir de mediados de la centuria siguiente. Las estimaciones de época nos hablan de unos 270 vecinos hacia finales del siglo XVII, lo que significaría quizá 1.300 habitantes. Pero en 1719, los reveses de la guerra de fronteras, por entonces en un momento decisivo, provocaron la huida de varios vecinos con sus familias, de suerte que sólo quedaban 300 hombres de armas, lo que implicaría una cifra aún menor de vecinos (Roverano, 1963). En esas dos décadas, por tanto, el crecimiento poblacional neto habría sido nulo o negativo; y todavía hacia 1750, luego de algunos años de paz relativa, la ciudad apenas contaba con una dimensión demográfica similar a la de medio siglo atrás ${ }^{12}$.

Para el período comprendido entre mediados del siglo XVIII e inicios del siglo XIX, a partir de los registros parroquiales y de las estimaciones que hemos mencionado, construimos curvas de crecimiento poblacional vegetativo y de stock demográfico según una tasa bruta de natalidad (TBN) del $45 \%$, menor que las de tres ciudades vecinas tomadas como sustento de inferencia, pero consistente con las estimaciones y con una demografía que, todo nos indica, fue menos dinámica que la de estas últimas. Los datos obtenidos figuran en Apéndice on line ${ }^{13}$. Además, la progresión de los saldos

10 Un ejemplo en Robertson (1920, pp. 91 y ss.). El diputado del Consulado de Comercio informaba que, por el ramo de arbitrios de la ciudad, se «cosecha al año veintte y cinco mil ps. enplatta Efectiba...» Agustin de Yriondo al Consulado de Buenos Aires, Santa Fe, 12/12/1799. En AGN, Consulado de Buenos Aires, Santa Fe, Corrientes, t. IV, ff. 112 v.-113 r., IX-4-6-4.

11 El historiador Vicuña Mackenna calculaba 400 vecinos o 2.000 habitantes para 1755 , dato tomado de Cervera (1907, p. 671). Maeder (1976) informa 1.500 habitantes para la ciudad y 6.356 para toda la jurisdicción en 1760; y Azara (1809, t. II, pp. 338-339) indica 4.000 sólo para la ciudad, aunque esta cifra pudo incluir las áreas circundantes.

12 Cervera (1907, t. I, pp. 435 y ss.) y Maeder (1976). Para 1710 se estimaba el consumo anual de ganado vacuno de la ciudad en 2.000 cabezas, pero la cifra parece muy pequeña. Cervera (1907, t. II, p. 98).

${ }^{13}$ Los datos de los hechos demográficos corresponden a los libros parroquiales de la Catedral de Todos los Santos de la ciudad de Santa Fe, y siguen conservándose allí. Los publicó Cervera (1907, t. I, pp. 672 y ss.). También existen copias digitalizadas de los microfilms de los libros originales en <www.familysearch.org $>$. Hemos confrontado estas últimas con los datos de Cervera y hemos corregido los errores obteniendo curvas de nacimientos (en rigor bautismos) y defunciones de toda el área urbana y su hinterland inmediato. La TBN de Paraná (1820) fue del 37,8\%o; la de Gualeguay del mismo año, del 54,97\%; y las de Buenos Aires, según el siguiente detalle: del 53,06\%o en 1720 ; del $51,53 \%$ en 1744 ; del $52,69 \%$ on 1750 ; del $63,15 \%$ en 1766 ; del $56,37 \%$ on 1778 ; del $57,27 \%$ en 1790 ; del $57,12 \%$ en 1800 y del $70,24 \%$ en 1810 (aunque el censo de este año es 
de los registros parroquiales (nacimientos menos defunciones), partiendo de una estimación de 2.000 personas para 1755 , ofrece una curva de crecimiento vegetativo de la población total de poco más del $2 \%$ anual, apenas algo menor de la que ofrece la de nacimientos considerando la ya indicada TBN del $45 \%$. De modo que podemos fijar, para 1810, una población estimada en un mínimo de alrededor de 6.200 y un máximo de unas 6.800 personas, considerando sólo el ámbito del casco urbano de la ciudad de Santa Fe y su entorno rural inmediato. En el largo siglo transcurrido desde 1700 hasta 1810, entonces, la tasa anual de crecimiento poblacional habría sido sólo de entre el 1,43 y el 1,52\%, muy inferior a la de otras ciudades cercanas. Es un poco sorprendente que esa falta de dinamismo poblacional se prolongara aun cuando la amenaza indígena ya había menguado; pero todo indica que nuestros cálculos son lo más cercano a la realidad que podría obtenerse en el estado actual del conocimiento. Seguramente, las zonas de frontera ofrecían mejores oportunidades de progreso material, ya que estas cifras sólo se refieren a la ciudad y a su entorno inmediato; durante la segunda mitad del siglo XVIII, el área rural más alejada tuvo una dinámica demográfica mucho más intensa, aunque aún no podamos expresarla en cifras.

\section{LAS FUENTES Y LA METODOLOGÍA}

En Santa Fe había, casi desde la época misma de la conquista, cuatro conventos de regulares: San Francisco, La Merced, Santo Domingo y el colegio de la Compañía de Jesús. Este último se cerró con la expulsión de la Orden de todos los dominios de España en 1767; mientras que los registros contables de Santo Domingo que han llegado hasta nosotros no empiezan hasta 1816. Contamos entonces con los libros de ingresos y gastos de $\mathrm{La}$ Merced y San Francisco cubriendo prácticamente todo el siglo, y los del colegio jesuita sólo durante la primera mitad. En general, se trata de registros diarios en los que se asentaron partidas individuales por cada una de las compras o ventas efectuadas. Éstas podían variar entre unas pocas unidades y cantidades considerables. Los registros se auditaban con regularidad. A veces se compraban bienes de consumo en partidas significativas, a precios $\mathrm{y}$ en medidas al por mayor; pero lo habitual era al detalle. Si bien los rangos de precios son similares en los tres conventos, para transacciones coincidentes en el tiempo, en algunos bienes políticamente estratégicos los

(footnote continued)

deficiente por pérdida de parte de la documentación original). Se tomó así un valor del 45\%o teniendo en cuenta que se trataba de una población menos dinámica que las nombradas, y la cifra de crecimiento demográfico resultante dio un valor, para 1794, similar al estimado por Félix de Azara. Los datos de 1820 para Entre Ríos en el Censo de 1820, en Archivo General de la Provincia de Corrientes, Censos, t. V; los libros parroquiales entrerrianos también en <www.familysearch.org> Las TBN de Buenos Aires se calcularon a partir de los datos provistos por Besio Moreno (1939). 
jesuitas consignaban a veces valores menores, como ocurre con la carne en épocas de carestía ${ }^{14}$. Como la información de las cuentas conventuales es débil para el período 1784-1802, hemos completado las series con datos obtenidos de libros de alcabalas y una contabilidad privada ${ }^{15}$.

Del amplísimo espectro de bienes registrados se seleccionaron aquellas series de precios mayoristas que, dentro del conjunto de las correspondientes a productos básicos, alcanzaron, antes de interpolación, un umbral mínimo de representatividad, a lo largo de todo el período, del $50 \%$ de años con datos, obteniéndose así series de 14 productos, seis de origen local y ocho de origen regional $^{16}$. Entre los locales, tenemos maíz (por fanega), grasa (botija), sebo (arroba), leña (carretada), trigo (fanega) y carne (res). En cuanto a regionales: cera (por arroba), sal (fanega), azúcar (arroba), bayeta (vara), tabaco (arroba), vino (botija), yerba mate (arroba) y lienzo (vara) ${ }^{17}$.

14 Esos casos no fueron descartados, ya que la diferencia no resultó excesiva. Los menores precios de la carne se debían a que, como los jesuitas poseían grandes estancias, a veces el Cabildo o el Teniente de Gobernador les asignaban un rol determinante en el abasto urbano. La carne vacuna tenía, en el área rioplatense, una importancia fundamental como bien alimenticio básico. En épocas de sequía, cuando la cosecha de trigo resultaba insuficiente, la pródiga presencia de cursos de agua salvaba en cierta medida al ganado. La abundancia relativa de carne cumplía así un papel equilibrador de la oferta alimentaria, reduciendo la dependencia de los cereales, cuya escasez, en otras regiones, a menudo derivaba en terribles hambrunas.

15 Véanse referencias detalladas en el apartado de Fuentes. Los libros de alcabalas registraban las guías emitidas fuera de Santa Fe que había que vender en esa ciudad o las emitidas en la propia Santa $\mathrm{Fe}$, a fin de enajenar esos bienes en otras plazas. Para evitar confusiones, hemos seleccionado únicamente las guías emitidas en Santa $\mathrm{Fe}$, con aforos en precios de la plaza local, y siempre cuidando de empalmar las series de unas y otras fuentes, lo cual no ofreció mayores problemas. Aunque los precios de las guías de alcabalas son fiscales, el empalme y la confrontación con otras fuentes mostró que no estaban muy lejos de los de mercado. La abundancia de datos muestra el importante papel de Santa Fe como centro de expedición o reexpedición de mercancías. Los datos de las cuentas del comerciante y estanciero Manuel Ignacio Diez de Andino corresponden a las compras hechas para abastecer a los peones de diversos emprendimientos productivos. Los precios obtenidos son, en todos los casos, mayoristas.

16 Es importante destacar que, para la división entre precios mayoristas y minoristas, el criterio no fue sólo observar la medida de capacidad respectiva sino el valor unitario comparado una vez reducido el producto a medida uniforme. Así, por ejemplo, la yerba tiene el mismo precio por arroba ya sea que haya sido comprada en arrobas (medida minorista) o en tercios (medida mayorista); el maíz, el mismo precio por fanega (mayorista) aun cuando la compra fuera medida en cuartillas, almudes o libras (minoristas). En cambio, otros productos muestran diferencias amplias, sólo atribuibles al hecho de que su compra en distintas medidas correspondía también a distintos circuitos: mayorista o minorista. La fanega de sal tenía un valor de 49 reales en 1707, mientras que el almud valía 6 reales; de modo que la fanega, a ese valor, llegaría a 72 reales. El vino por botija costaba 105,7 reales en 1712; y por frasco, 8 reales. A 18 frascos por botija, este último precio la haría subir hasta los 144 reales. Si bien las diferencias entre la medida minorista y mayorista fluctúan en el tiempo, queda muy claro que algunos productos sólo se adquirían a valores mayoristas.

17 Los productos de origen regional se definieron a partir de las mismas fuentes (cuando mencionaban ese origen) o de datos en los inventarios o la bibliografía (por ejemplo, Cervera, 1907, t. I, pp. 445-456). Así, la cera provenía de Santiago del Estero (se descartó la cera «de Castilla» por su diferente calidad y precio); la sal, de las salinas pampeanas o cordobesas (la europea también se descartó por las mismas razones); la yerba y el tabaco, del Paraguay (el último, estancado por el estado colonial a partir de 1779); el lienzo, de Misiones o del Alto Perú (sin diferencias de precio ni, 
Los precios promedio anuales de cada producto se obtuvieron ponderando las partidas, de las cuales se salvaron los errores y se descartaron las que ofrecían datos incongruentes. Si bien existen unos pocos años en los que sólo se registraron una o dos transacciones de un bien determinado, en la mayor parte de los casos los precios surgieron de al menos tres transacciones distintas, razonablemente distribuidas a lo largo del año ${ }^{18}$. Los valores se asentaron en reales de plata de a ocho por un peso y $3,38 \mathrm{~g}$ del sistema métrico, de los cuales $3,10 \mathrm{~g}$ de plata fina; el debasement secreto de 1772 redujo ese último valor a $3,05 \mathrm{~g}$; y el de 1786 , a $3,03 \mathrm{~g}^{19}$. Los datos que faltan se suplieron mediante interpolación lineal simple, y se aceptaron hasta tres interpolaciones seguidas.

Es importante indicar desde ahora que, a pesar de que algunos testimonios insisten en la falta de circulante metálico, no parece que dicha situación haya sido la norma ${ }^{20}$. Aunque Santa $\mathrm{Fe}$ se encontraba lejos de las fuentes de producción de plata, tanto al inicio como al final del siglo hay pruebas de la existencia de circulante metálico, que se menciona cada vez con mayor frecuencia y en cantidades más sustanciosas a medida que transcurre la centuria ${ }^{21}$.

\section{(footnote continued)}

es de pensar, de calidad, entre ambos); el vino, de Córdoba o Cuyo, comercializado en botijas de 18 frascos (se descartaron los casos de vino «de Málaga» o "de Italia», comercializados en recipientes de medida menor, pero con precio unitario mucho mayor); el azúcar, del Paraguay (se descartaron las partidas provenientes del Cuzco, por tratarse de entradas excepcionales y con precios mucho más elevados). La carne se registraba en reses (media res, cuarto de res, res), aunque también por arroba; pero esta última no se incorporó, puesto que se desconoce en cada caso cuántas arrobas se habían obtenido del animal sacrificado. La discriminación en productos de origen local, regional o ultramarino (la última no construida en nuestro caso por falta de masa crítica) la propuso Arcondo (1992) en 1968 y la retomaron luego otros investigadores. Para quien esté interesado en convertir las medidas al Sistema Métrico Decimal: 1 fanega (áridos) = 173,7 kg (trigo); 185,3 kg (maíz en grano); 1 arroba $=11,49 \mathrm{~kg} ; 1$ botija $=42,75 \mathrm{l} ; 1$ vara $=0,87 \mathrm{~m}$. Para la leña no hay equivalencia en kilogramos; en todo caso, 1 carretada $=400$ piezas (leña «de poblado» en trozos). Sobre equivalencias de pesos y medidas, véase Djenderedjian y Martirén (2013).

18 Preferimos no descartar los años en los cuales sólo había uno o dos registros, ya que en todos los casos los valores se mostraron solidarios con los anteriores y posteriores; y, por otro lado, siendo el objetivo principal de este trabajo la reconstrucción del movimiento secular de los precios mayoristas, incluso una diferencia más o menos significativa en un año puntual no hubiera alterado demasiado la tendencia.

19 Esos cambios en el porcentaje de metal fino, lógicamente, no se reflejan en nuestras series, ya que los valores se registraron en reales. Pero el investigador interesado en convertir los precios a gramos de plata deberá tenerlos en cuenta. El peso fuerte columnario (acuñado entre 1732 y 1772), con valor facial de 8 reales y ley de 11 dineros (o 916,666 milésimos de fino), pesaba 27,064 g del Sistema Métrico Decimal; el peso fuerte de busto que comenzó a acuñarse en 1772 tenía el mismo peso, pero una ley de sólo 10 dineros y 20 granos, o 902,777 milésimos de fino; mientras que las acuñaciones efectuadas a partir de 1786 rebajaron la ley a 10 dineros y 18 granos, u 895,832 milésimos. En Burzio (1958, t. II, p. 181) y Romano (1998, p. 120).

${ }^{20}$ El misionero Florian Paucke, que vivió en Santa Fe entre 1747 y 1767, escribió: «tan poco dinero existe entre las gentes vulgares... que en la mayor parte... se trueca una cosa por otra...» (Paucke, 1942-1944, t. I, p. 143).

21 Si bien en las actas del Cabildo de inicios del siglo XVIII se sigue mencionando a menudo la falta de moneda acuñada y se proponen sustitutos, en los conventos se registran, ya desde esos años y de forma regular, diversos importes de plata efectiva en caja para hacer frente a los gastos corrientes; buena parte de las misas se pagan en dinero y los salarios de los trabajadores también. 
El simple hecho de que, durante todo el período, las contabilidades santafesinas se llevaran en pesos de plata y no en «moneda de la tierra» es un indicativo de que aquéllos nunca dejaron de ser la moneda predominante; quizá no siempre en la masa del circulante, pero sí como equivalente general, y en las transacciones al mayoreo ${ }^{22}$. De modo que podemos aceptar que las series de precios corresponden a transacciones en su totalidad nominadas - y de hecho, sin duda, en gran parte, realizadas - en plata acuñada. Los datos obtenidos figuran en el Apéndice on line.

\section{LOS PRECIOS MAYORISTAS EN EL LARGO PLAZO}

El gráfico 1 presenta la evolución de los precios mayoristas (en un índice general, otro de precios de bienes locales y otro de bienes regionales) según la fórmula de Jevons ${ }^{23}$. No optamos por las fórmulas más usuales de Laspeyres o Paasche porque reflejan los cambios de una canasta de bienes. Ésta no resulta útil en nuestro caso, pues a lo largo del tiempo le afectan distorsiones que algunas veces son de gran magnitud; en el caso de los jesuitas, por ejemplo, por el muy notable papel comercial de la Orden ${ }^{24}$. Pero, además, al ser todos los conventos comunidades muy pequeñas (apenas con una docena de miembros), cualquier acontecimiento (construcción

\section{(footnote continued)}

Los remates de los diezmos, asimismo, se asientan en plata y es habitual que se especifiquen cantidades pagadas en efectivo. El porcentaje pagado en dinero de los salarios privados parece haber sido poco significativo hasta mediados del siglo, pero al final del mismo avanza hasta constituir, al menos en algunos casos, buena parte de la totalidad. Y, desde la década de 1780, se registran en la cárcel pública varios casos de prisión por tráfico de moneda falsa, otro indicio de la amplia extensión del circulante acuñado. Por desgracia, no es posible aún efectuar estimaciones de M0. AGN, Testimonios de remates de diezmos, Clase IV, 1618-1749, IX-13-3-2, expedientes de 1703 , f. 8, y 1749, f. 10; AGPSF, Contaduría, t. VII, años 1739-1766 y 1750-1766, leg. 1, f. 2; íbid., t. IX, años 1774-1786, leg. 1; debate sobre el pago en efectivo de los sueldos de la Compañía de Dotación en AGPSF, Actas del Cabildo, 11/01/1778, t. XIV B, ff. 529-531; cuentas de peones de un beneficio de maderas, AGPSF, Colección Diez de Andino, carpeta 49; presos en la cárcel por falsificación de monedas en 1785-1794, en Actas del Cabildo, AGPSF, t. XV A, ff. 166-167; XVI A, ff. 262v-263.

22 Señalar esto es pertinente porque otras economías cercanas registraban contablemente las transacciones en "pesos provinciales» o "moneda de la tierra», incluso en época tardía, aun sin especificar la diferencia entre ambas, cosa que provoca a menudo confusión entre los investigadores. Ver al respecto Djenderedjian (1997-1998).

${ }^{23}$ Como se sabe, el índice de Jevons se calcula como el promedio geométrico del precio relativo del período $t$ y el del período base $O$ (siendo $n$ el número de índices que se promedian):

$$
P_{J}=\prod\left(\frac{p_{t}}{p_{0}}\right)^{1 / n}
$$

${ }^{24}$ La Compañía de Jesús manejaba volúmenes impresionantes de mercancías, operando como una gran empresa comercial a gran escala en un área geográfica mucho más amplia que la de Santa Fe. También tenía fuerte peso en la comercialización local: en ciertas coyunturas críticas, entre 1740 y 1744, por ejemplo, el Cabildo solicitó a la Compañía que proveyera carne al mercado de abasto de la ciudad. AGPSF, Actas del Cabildo, enero de 1740 a enero de 1744, t. X B, ff. 495-497; t. XI, ff. 114-211. 


\section{GRÁFICO 1}

ÍNDICES DE PRECIOS MAYORISTAS. SANTA FE, 1700-1810 (BASE $1761=100$ )

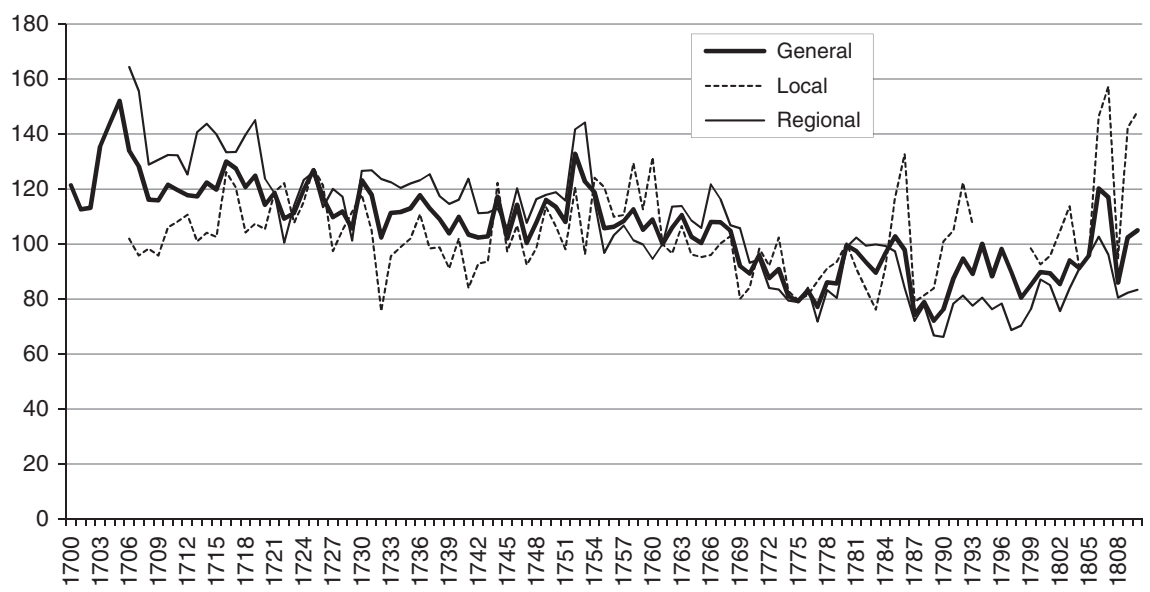

Fuentes: AGPSF, Contaduría, t. 6 (cuentas conventuales de los jesuitas); AGOM (mercedarios); CSF (franciscanos), guías de alcabalas y contabilidad privada. Véase detalle en sección Fuentes y datos en Apéndice on line.

Nota: índice general, índice de precios de productos locales (maíz, sebo, leña, trigo, carne, grasa) e índice de precios de productos regionales (cera, sal, azúcar, bayeta, yerba, lienzo, tabaco, vino), calculados para años con datos de más de dos productos, en series con hasta tres interpolaciones seguidas. No se elaboró un índice de productos ultramarinos por falta de datos consistentes para la segunda mitad del siglo XVIII. Se eligió como base el año 1761 porque es relativamente «normal» (ya que no le afectan coyunturas bélicas o climáticas) y porque en él los precios de mayor cantidad de series se acercaron al promedio.

o reparación de edificios, abasto de alguna de sus otras propiedades urbanas o rurales, incorporación transitoria de personal, alojamiento de viajeros, comisiones gubernamentales, celebraciones y fiestas) generaba gastos considerables en determinados momentos o en determinadas partidas, por lo que las diferencias en ciertos rubros son, en algunos años, abismales con respecto a la mayor parte de los demás de la serie ${ }^{25}$. Esto, que es una característica propia de las fuentes con las que tratamos, desfigura las canastas de gasto a la hora de utilizarlas en un índice; por eso, fórmulas que no las consideran resultan en

25 Algunos ejemplos darán cuenta del peso de estas distorsiones. En 1722, el convento de la Compañía compra 2.012 arrobas de sebo, cuando las transacciones normales eran de entre 40 y 100 , y el consumo de la propia comunidad no debía superar las 4 o 5 arrobas anuales; en 1807, los conventos de La Merced y San Francisco gastan en total 8 arrobas de cera en grandes festejos, cuando lo normal en años anteriores había sido de sólo media arroba o menos cada uno; en 1784, el de la Merced compró 102 arrobas de sebo, y el de San Francisco 20, con lo que el total de gasto del año multiplicó por 20 los del anterior. 
este caso más adecuadas para dar cuenta de la evolución general de los precios $^{26}$.

En primer lugar, la tendencia descendente a lo largo del siglo es un fenómeno que ya ha sido reportado para otras ciudades sudamericanas, lo que confirma la existencia de recorridos divergentes con respecto a los precios del Atlántico norte hasta, aproximadamente, $1776^{27}$. Luego, el movimiento descendente se detiene y se ingresa en un período de volatilidad, con tendencia alcista creciente. Este remoto rincón rioplatense se acopla así, muy tarde, a la llamada «revolución de los precios» del siglo XVIII ${ }^{28}$. Los datos para la década de 1790 muestran los fuertes procesos de volatilidad que caracterizarían el final de aquella centuria y el comienzo de la siguiente, y que, por lo que sabemos, habrían de continuar al menos en ciertos insumos alimenticios básicos hasta mediados del siglo $\mathrm{XIX}^{29}$.

$\mathrm{El}$ análisis de las tendencias seculares santafesinas pone de relieve una importante diferenciación en los precios de los productos por su origen, evidente sobre todo en ciertas coyunturas; una secuencia decreciente más marcada y persistente para los precios regionales (con excepciones, de las cuales la más notable es 1777-1783) y una mucho más cíclica en los precios locales, que de todos modos no enmascaran derivas de mediano o largo plazo (como el ciclo inflacionario del segundo cuarto del siglo XVIII y el deflacionario del siguiente).

El primer período, que llega aproximadamente hasta 1730, muestra una convergencia entre los precios regionales y los locales; estos últimos (sobre todo en el caso del trigo) podrían estar afectados por el período más intenso de la guerra que se extiende de 1715 a 1733; no tanto por destrucción física sino por problemas estructurales de la oferta, ligada al estancamiento, o aun descenso, de la población, en especial de la rural. La guerra impactó así sobre el acendrado papel de Santa Fe como localidad clave del intercambio a mediana y larga distancia, encareciendo los costos de transporte o de transacción: pensemos que los convoyes estaban sujetos a una alta probabilidad de sufrir pérdidas. Tras lograr una paz relativa hacia 1735 , la volatilidad se acelera desde 1743 y se mantiene durante toda la década de

26 Por lo demás, los índices de Laspeyres o Paasche no redimen las limitaciones propias de las fuentes en algunos de los estudios disponibles, por lo que las comparaciones, aun utilizando esos índices, no estarían sin duda exentas de controversia. De todos modos, hemos construido ambos índices para nuestro caso y, más allá de las distorsiones que hemos apuntado, ambos mostraron la misma tendencia descendente de largo plazo, con similares puntos de ruptura, que es lo que nos interesa aquí analizar.

27 Véase, por ejemplo, Cuesta (2009) y Johnson y Tandeter (1992).

28 Para Sudamérica, véase, por ejemplo, Cuesta (2009) y Johnson y Tandeter (1992); para Europa y los Estados Unidos, Fischer (1996, pp. 121 y ss.); para México, Dobado (2010, pp. 85-102). Gallo y Newland (2004) ya habían mencionado las dificultades para la convergencia de precios entre la península Ibérica y sus colonias sudamericanas, en contra de una convergencia interna creciente.

${ }^{29}$ Sobre las fuertes fluctuaciones del trigo en la primera mitad del siglo XIX, véase Djenderedjian (2008). 
1750, incluyendo una a menudo fuerte divergencia en las trayectorias de los precios locales y regionales, al menos hasta 1762. En aquellos años, a la deriva de los precios locales le afectaron varias sequías catastróficas: los precios del trigo alcanzaron en 1759 casi 60 reales por fanega, mientras que los del maíz llegaron a 48, niveles que sólo volverían a superarse entrado el siglo $\mathrm{XIX}^{30}$. Pero esto no impediría más tarde el descenso del índice local desde sus picos de 1758-1760 hasta 1775; y la evolución, también descendente, de los precios de los bienes regionales provocaría una fuerte caída del índice general hasta comienzos de la década de 1780. Durante el último tramo del siglo XVIII, y en los inicios del siguiente, las fluctuaciones se vuelven más violentas y la tendencia inflacionaria, más fuerte. Se había entrado, sin dudas, en una nueva dinámica marcada, entre otras cosas, por una creciente integración en la economía internacional, como ya se puso de relieve (Halperin Donghi, 1979).

Sin embargo, la larga situación deflacionaria de ese tercer cuarto del siglo XVIII todavía es una de las incógnitas más misteriosas del período. Se trata de un largo momento de lenta convergencia con los también descendentes movimientos de precios de otras ciudades cercanas (en especial, Córdoba, de la que contamos con datos hasta 1762; y, en parte, Buenos Aires) y, sin duda, una etapa en la que se expanden la población y la producción, ocupando o reocupando territorios. Parece que esos procesos fueran la expresión numérica de una cierta recomposición de los espacios productivos y comerciales con un nivel de actividad creciente en ambos. Lo curioso es que ese largo ciclo deflacionario se produjo, además, en un contexto en el que, según abundantes evidencias, hay un aumento progresivo del circulante metálico $^{31}$. Sobre lo cual, además de lo ya dicho en la nota 21 , agregamos el aumento en la producción de plata de las minas de Potosí y el consiguiente crecimiento de la demanda de bienes de todo tipo por parte de la economía de ese páramo altoperuano, en pago de los cuales se derramaba la plata del Cerro Rico a lo largo y ancho del territorio rioplatense ${ }^{32}$. Es evidente que también aumentaron las salidas de plata hacia Europa; pero, como dijimos,

30 Conviene señalar que, durante todo el siglo XVIII, los precios del trigo de 1759 sólo se superaron en la dura coyuntura de 1749-1752 y, anteriormente, en 1722, en el punto más intenso de la lucha de fronteras.

31 Es decir, las mismas circunstancias que produjeron (o al menos reforzaron) en Europa, según diversos autores, un aumento sostenido de los precios durante el siglo XVIII (en Santa Fe en particular y en el área rioplatense en general) habrían provocado (o al menos no pudieron revertir) una marcada tendencia decreciente. Véase, por ejemplo, Fischer (1996, pp. 126-130).

32 Sobre la tendencia de los precios cordobeses, Arcondo (1992); sobre los porteños, Cuesta (2009). Según los datos de los reales quintos (diezmos luego de 1736) y cobos $(1,5 \%)$ a la producción de plata extraída del cerro de Potosí, ésta pasó de unos 165.000 pesos anuales en promedio para los años 1700-1709 a unos 295.700 pesos para los años $1771-1780$, y a 308.400 para el período 17911800. Datos tomados de Burzio (ed.) (1971). Los trabajos que refieren la circulación de plata potosina en el ámbito rioplatense son bastante abundantes, citemos aquí sólo a un clásico, Assadourian (1982). 
todo apunta a que el circulante metálico, a nivel local, adquiere mayor presencia $^{33}$.

\section{PRODUCCIÓN Y PRODUCTIVIDAD}

Aumento de la masa monetaria, descenso de precios. Eso sólo podría corresponder a un aumento de la producción per cápita que haya superado al incremento relativo de la oferta monetaria. La deflación, así, aparecería ligada a un crecimiento económico basado en mejoras de productividad (Friedman y Schwarz, 1963). Ello nos lleva, en primer lugar, a repensar los índices de producción agraria. Si bien, como hemos visto en el apartado 2, la población santafesina creció muy modestamente a lo largo de este período, incluso una ganancia demográfica pequeña, en un contexto de frontera abierta y de ocupación de nuevas tierras, debió producir ganancias de productividad paralelas. Asimismo, la convergencia de las tendencias de precios con las de Córdoba y, sobre todo, Buenos Aires (cuya demografía se expande por entonces a buen ritmo), pudo ser posible con, también, mayores índices de producción per cápita, tanto local como regionalmente. Examinaremos esto a través de los datos del trigo (Gráfico 2).

Los datos diezmales del trigo, deflactados por precios, muestran un aumento relativo en la producción absoluta y per cápita, pero sólo en el período comprendido, aproximadamente, entre 1770 y 1790 , con un descenso desde entonces hasta comienzos del siglo XIX y una marcada volatilidad para el período anterior ${ }^{34}$. Esto así no explicaría el origen de la tendencia decreciente de los precios en torno a mediados del siglo XVIII. ¿Ese origen estaría, acaso, en otros productos? La producción de ganado, sin duda el otro rubro más importante de la producción local (en razón de la transabilidad de los cueros y del peso de la carne como alimento), estimada a partir de los datos de los remates de diezmos, crece desde un promedio de

33 De cualquier modo, queda pendiente de investigación el incremento de la salida atlántica de plata, la cual es imposible de medir hoy por la importancia del comercio directo; es decir, no registrado.

34 Pasando de un rango 0,3/0,5 fanegas santafesinas por habitante en promedio anual en las décadas de 1750-1760 a uno de 0,4/0,6 fanegas en la de 1770. Se trata de los remates de los diezmos de granos (descontando el maíz), efectuados separadamente de los de la producción hortícola y, por lo tanto, compuestos en muy alta proporción por trigo. Si bien todavía en los primeros años del siglo XVIII el diezmo del maíz era importante, muy pronto el trigo lo superó. Tanto diezmos del trigo como del ganado se deflactaron por los precios correspondientes. Se trata de los diezmos de las chacras de la ciudad de Santa Fe y de los «pagos» de Rincón, Salado, Coronda y Paraná, que corresponden al área de abasto que circunda la ciudad. No se tomaron los diezmos de Arroyos ni de Rosario, demasiado alejados hacia el sur, ni los correspondientes a la propia ciudad de Santa Fe, es decir, a las quintas; los primeros, sin embargo, alcanzaban a menudo la ciudad, por lo que el aumento en el rango per cápita debería ser aún mayor. AGN, Diezmos, Clase IV, Testimonios de remates, 1618-1749, IX-13-3-2; íbid., 1750-1800, IX-13-3-3; AGN, Quadrante de Diezmos, IX-7-3-2 (para el período 1801-1810). 


\section{GRÁFICO 2}

PRECIOS DEL TRIGO, SANTA FE, 1700-1810; PRODUCCIÓN DE TRIGO PER CÁPITA ESTIMADA, 1712-1810. PROMEDIOS TRIENALES.

BASE $100=$ PROMEDIO

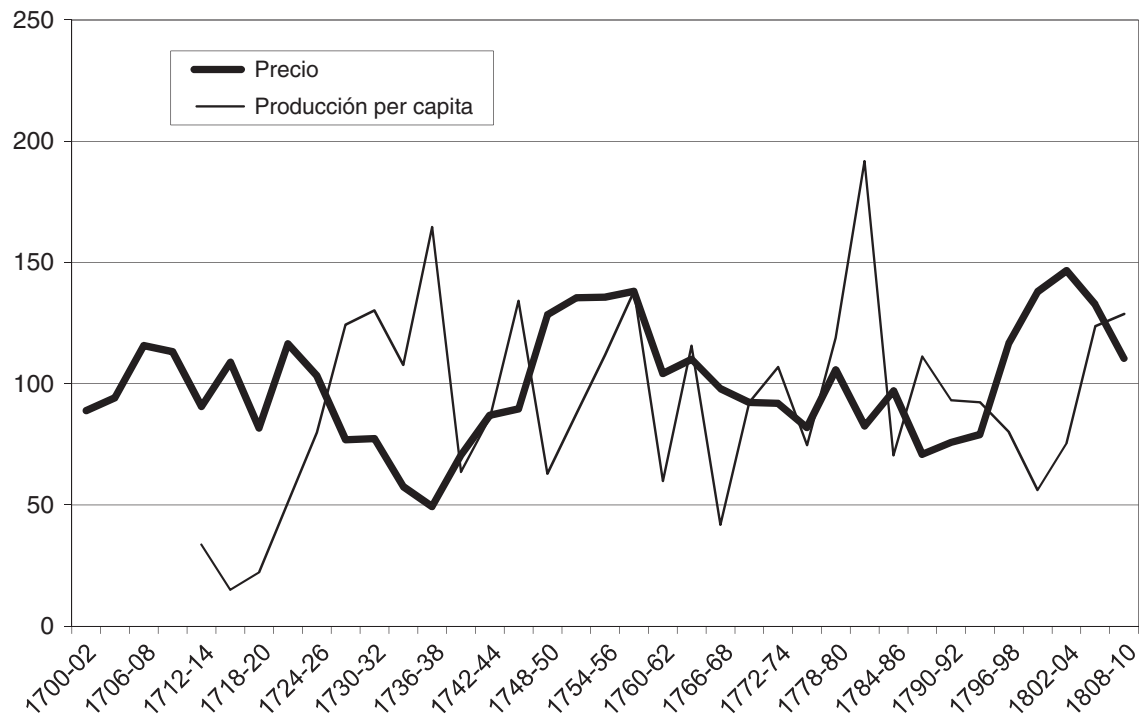

Fuentes: Para los diezmos del trigo, AGN, IX-13-3-3 y IX-7-3-2; y AGPSF, Contaduría, tt. 7 y 9. Para la población, Cervera (1907), t. I, pp. 672 y ss., datos confrontados con los registros originales existentes en la Catedral de Todos los Santos de la ciudad de Santa Fe, disponibles en copias digitalizadas en <www.familysearch. org > (acceso diciembre 2013 a mayo 2014). Para los precios, véase Gráfico 1. Todos los datos figuran en el Apéndice on line.

Nota: datos de producción a partir de diezmos de granos deflactados, según se indica en el texto. Población: desde 1755, estimada a partir de promedio de $\mathrm{TBN}=45 \%$ y vegetativo. Antes de 1755 , con aplicación regresiva de tasas promedio del período posterior.

alrededor de cuatro reses por habitante y año en la década de 1750 hasta entre siete y diez a mediados de la de 1760 (no hemos incluido el gráfico por razones de espacio). Pero, luego, las cifras descienden al comenzar la década siguiente. Dada la gran importancia cuantitativa de la producción ganadera, estos datos relativizan aún más el peso de los escasos avances habidos en la producción de trigo. Quizá, entonces, el descenso de los precios locales responda, primero, a aumentos en la productividad del ganado vacuno y, después, en el trigo.

De todos modos, esto explicaría los movimientos de los precios locales, pero no los regionales. Los ciclos de la producción regional son muy diversos: el lienzo de Misiones Guaraníes, por ejemplo, sufrió en estos años los 
embates de varios sucesos terribles, como las rebeliones comuneras del Paraguay (1717-1735), diversas epidemias (como las muy duras de 1734 o 1737), la guerra, que fue consecuencia de la aplicación del Tratado de Permuta (1750-1756), o la expulsión de los jesuitas y la aparición de administradores seculares, que provocaron el colapso de la economía misional $^{35}$. La producción de yerba también sufrió duros altibajos ${ }^{36}$. No es de extrañar así que la desviación estándar de la serie de precios regionales hasta 1780 sea de 18,3 frente a los 12,5 de los locales. Sin embargo, ninguna de esas circunstancias parece exceder demasiado las fluctuaciones lógicas en una economía de base orgánica y, por tanto, plenamente expuesta al impacto de los ciclos más extremos de la naturaleza; no explican así, tampoco, la tendencia descendente de los precios en el largo plazo. Ni parecen hacerlo las particulares condiciones de la frontera indígena, algo que coincide con lo que conocemos sobre otras ciudades ${ }^{37}$. No tenemos aún, de ese modo, una explicación completa.

A partir de inicios de la década de 1780 comienza un período de mayor volatilidad y de mayor presión inflacionaria que, en parte, al menos, puede atribuirse a incrementos en la demanda que rebasaron una oferta que no crecía al mismo ritmo ${ }^{38}$. Las series de precios locales y regionales comienzan, además, a divergir más intensamente, y los primeros a mostrar mayor volatilidad. En el período 1781-1810, la desviación estándar es de 23,3 para los locales y de 10,9 para los regionales. Este cambio estructural se montó, como ya se ha dicho, sobre la apertura a mercados más lejanos y el alargamiento y adensamiento de las líneas de comercio: los recursos locales que se valorizan son mayormente transables (están expresados en nuestra serie por los proxies del ganado, es decir, carne, grasa y sebo; y, en menor medida, el trigo, que en momentos de carestía podía trasladarse por vía fluvial con costos de transporte bajos). Es probable que en esta evolución tengan parte mejoras en la navegación fluvial y descensos en los costos de transacción por medidas liberalizadoras simbolizadas localmente en la

35 Sobre el tema, véanse Ganson, (2003) y Wilde (2009).

36 Por ejemplo, en 1747, con precios en un nadir secular de menos de 6 reales por arroba, se comentaba burlonamente sobre los paraguayos, en Santa Fe, que «mas estimaciones tendría cargar la tierra en sus embarcaciones que dho. fruto de yerva...» Citado por Susnik (1990-1991, p. 75).

37 La guerra de fronteras parece que tuvo un impacto relativamente menor en los precios de los bienes locales, ya que, a su pesar, la tendencia general es a la baja y las fluctuaciones, si bien muy pronunciadas, sobre todo en ciertas coyunturas, no coinciden necesariamente con los momentos de mayor conflictividad. Véase Djenderedjian y Martiren (2013). Conviene destacar que la desviación estándar de un producto local (el trigo) es similar a la de Córdoba, ciudad vecina que no sufrió embates indígenas; sin embargo, a los precios del ganado parece que les afectó de forma más estructural.

38 Algunos testimonios de la época sugieren que el fin del puerto preciso en 1780 provocó escasez de productos traídos de otras partes, como la yerba. Véanse, por ejemplo, Azara (1873, p. 21) y Cervera (1907, t. II, Apéndice on line). Pero esto, en todo caso, no explica por qué esos altos precios de los bienes regionales se prolongan hasta 1810, ni por qué los productos locales también suben. 
anulación del privilegio de puerto preciso y, a nivel regional y continental, por la apertura legal al comercio recíproco entre el puerto de Buenos Aires y los de otras ciudades americanas y españolas, que valorizó los recursos rioplatenses en el mercado internacional ${ }^{39}$.

Pero esto no sólo sería consecuencia de la renovación borbónica, cuyo punto de partida se sitúa tradicionalmente en la fundación del virreinato en 1776, sino que tendría bases mucho más antiguas. En efecto, todo apuntaría a que, más que un aumento sustancial de la productividad, en el período 1750-1780 hubo un lento cambio cualitativo en las bases profundas del sistema comercial colonial: en primer lugar, el avance sobre recursos subutilizados, traído por la ampliación de las líneas de frontera a raíz del descenso de la conflictividad con los indígenas. Este avance, sustentado también en un leve pero constante incremento demográfico, posibilitó una creciente eficacia en el uso de los recursos. Pero también debió producirse una mejora sustancial en las ganancias del comercio de intermediación, ya fuera por razones políticas o, más probablemente, por una mayor frecuencia en los intercambios, contactos más fluidos y circulación más rápida de la información, en una región en la que los núcleos poblados alcanzaban, por fin, cierta importancia cuantitativa. Lo cual permitió contar con mercados más eficientes, y quizá incluso con algunas modificaciones en la logística de transportes por un mayor uso de economías de escala. Todo ello posibilitó descensos en los márgenes de intermediación, que se replicaron en los precios al mayoreo de varios bienes regionales. Probablemente, desde 1767, la liberación de nichos de oportunidad generados por la desaparición de ese gran operador extremadamente concentrado que era el sistema jesuita abrió grandes posibilidades para la iniciativa individual y la competencia entre actores, contribuyendo a profundizar el descenso de precios. Las características oligopólicas de esos mercados de larga distancia fueron así atenuándose sin, obviamente, desaparecer por completo. Esto, sin duda, debiera también relacionarse con un aumento de los contactos con el exterior, que, por un lado, aumentaron la oferta local de bienes transables y, por otro, aumentaron el valor relativo de la plata exportable, por lo que tendieron a reducir el precio del resto de bienes. Eso conformaría así un ciclo de crecimiento de ancien régime sin cambio tecnológico importante, basado fundamentalmente en ganancias en la productividad de los factores por reducción de costos de transacción y aumento de los márgenes de intermediación, como lo retrató Hoffman (2000, pp. 143-200) para la Francia del siglo XVIII.

39 Esa coyuntura también está marcada, a partir de 1776, por la expedición militar de Pedro de Cevallos, que, como remarcó Cuesta (2009), impactó fuertemente en los precios de Buenos Aires por su misma dimensión (el grupo de soldados, oficiales y funcionarios que involucró equivalía a casi la mitad de la población existente allí a su llegada), y por la subsiguiente creación del virreinato del Río de la Plata, con la profunda reorganización administrativa, política y militar de la región que trajo aparejada. 
Todo esto fue el preámbulo de un largo ciclo de crecimiento que, desde el final del siglo XVIII, y con el afianzamiento de la apertura atlántica, puso de relieve las ventajas comparativas de la región para producir determinados bienes (cueros, carne salada, luego lanas, más tarde cereales) que habrían de definir, por largo tiempo, su perfil en el mercado mundial. Por lo que hemos visto, pareciera que algunas instituciones económicas coloniales (en especial, los mercados) lograron incrementos de eficiencia en el área rioplatense ya desde mediados del siglo XVIII, bastante antes de lo que la generalidad de los historiadores económicos ha admitido. Por eso, creemos que el análisis de ese período culminante de los años finales del régimen colonial no debiera estar aislado del medio siglo anterior, en el que, como parece, se fueron sentando sus bases.

\section{SALARIOS Y NIVELES DE VIDA}

Ese crecimiento debió afectar también, necesariamente, a los niveles de vida. ¿Hasta qué punto se reflejó en el salario (creciente expresión del valor del trabajo en una economía cada vez más mercantil) y en su poder de compra? Los datos existentes (que figuran en el Apéndice on line), bastante dispersos y aislados, no alcanzan a conformar una serie; pero cubren, de una u otra forma, distintos momentos del período y nos permiten obtener así ciertas precisiones al respecto.

Sin embargo, antes es necesario efectuar algunas aclaraciones. El salario monetario, como medio de vida, no es lo mismo en México, en Londres o en Santa Fe en cualquier momento determinado del siglo XVIII, así como tampoco lo es en cualquiera de esos sitios pero en años distantes de esa centuria. En primer lugar, al menos en Santa Fe, no incluye elementos fundamentales, como los alimentos del trabajador y sus «vicios» (yerba mate y tabaco), provistos gratuitamente por el empleador; por otro lado, los costos de "alojamiento» y de vestimenta son mucho menores en una Santa $\mathrm{Fe}$ colonial donde las temperaturas rara vez bajaban de $10^{\circ} \mathrm{C}$ y en la que había abundantes tierras periféricas baldías, en las que las ligeras inclemencias del tiempo podían soportarse con comodidad bajo una cubierta de ramas y hojas recogidas en los bosques. Esos barrios periféricos, por lo demás, estaban siempre a corta distancia del centro, lo que no ocurría en ciudades muy populosas. El valor del dinero recibido cambiaba, obviamente, en función de la extensión del uso de la moneda metálica. Y queda claro que el salario de un varón adulto no era igual al ingreso familiar, que obtenía recursos de múltiples expedientes. Lo que aparece constantemente en las fuentes es, por un lado, una orientación mercantil muy marcada en las explotaciones familiares (con superficies productivas destinadas principalmente a bienes transables: ganado y trigo); y, por otro lado, una función muy peculiar del salario en dinero: la apertura de cuentas corrientes para obtener bienes a 
crédito (ropas y enseres domésticos) ${ }^{40}$. Es decir, el salario es sólo una parte dentro de un esquema enormemente complejo de supervivencia, y aun de acumulación, puesto en marcha por un grupo que excede con amplitud al propio asalariado. Esto, además, sin considerar el hecho de que los patrones de consumo, y por tanto lo que cada individuo o sociedad considera imprescindible, varían también enormemente, como ha apuntado DobadoGonzález (2015). Más aún en una economía orgánica, con fuertes oscilaciones dentro de una estructura asimétrica de precios: ¿cómo determinar cuánto de qué alimento era reemplazado por cuál otro y a partir de qué costo? Y esto, por supuesto, sin introducir aún en la ecuación cuestiones más puramente culturales.

Dicho esto, creemos que una comparación sólo efectuada por medio de «canastas de huesos desnudos» (o barebone baskets, BBB, definidas en los términos de Allen et al., 2005) no sería suficiente. Por eso hemos calculado, además, siguiendo el método de Dobado y García (2014), el poder de compra del salario en kilos de maíz, trigo y azúcar. La carne, de la que sólo poseemos datos en reses, no pudo incluirse porque se desconocía su peso en kilos; pero para el cálculo de la BBB contamos con los gastos en carne de un obraje maderero a finales del siglo XVIII, y un recuento de la necesaria para alimentar a un regimiento santafesino en 1773, que nos permiten acercarnos al consumo diario ${ }^{41}$.

Nuestra muestra abarca salarios de varones en las categorías ocupacionales más bajas (peón, albañil). Siguiendo a Arroyo Abad et al. (2012), suponemos una BBB de alrededor de 2.000 calorías diarias por persona a inicios del siglo XIX, que se cubría anualmente con $132 \mathrm{~kg}$ de trigo y $105 \mathrm{~kg}$ de carne $^{42}$. Si bien nuestra serie de precios de la carne llega sólo hasta 1781, a fin de no desaprovechar los datos de salarios y cereales de comienzos del siglo XIX, supondremos que la carne valía, para esos años (1805-1808), el precio promedio de toda la serie ${ }^{43}$. Calculamos, de ese modo, el costo de la canasta en gramos de plata, a fin de poderlo comparar con los cálculos de

40 Al respecto, véanse Garavaglia (1999) y Djenderedjian (1997-1998). Son muestras típicas de bajo valor relativo de la tierra y carestía del trabajo.

41 El consumo diario rondaba los $300 \mathrm{~g}$, coincidente con los cálculos de Arroyo Abad et al. (2012). AGPSF, Diez de Andino, Carpeta 1, leg. 18, f. 22, «Relazon. de las carretas, qe. se nececitan pa. condusir un mes de viberes...», AGN IX-4-1-4, Santa Fe, leg. 6, 1771-1773, sin foliar. Los contadores reales afirmaban que de una res se obtenían 60 raciones, pero esto sólo daría un rendimiento de $18 \mathrm{~kg}$ de carne por res, lo cual parece muy poco. Aguirre (1949-1950 [1793-1798], t. II, 2. ${ }^{\text {a }}$ parte, p. 268).

42 Aceptamos así, sin crítica, los cálculos de Arroyo Abad et al., hechos para Buenos Aires. No parece irrazonable suponer que también fueran similares en Santa Fe. No hemos postulado ni calculado cambios en la canasta a lo largo del tiempo, pero el poder de compra en cereales alternativos al trigo (maíz) puede dar una idea al respecto del costo de oportunidad relativo en cada año.

43 Esto es: 11,17 reales. No podemos reducir a valor por res los datos que poseemos de diversas fuentes; pero el gasto diario permite suponer que ese precio promedio no se alejó demasiado del real. Además, es menester tener en cuenta la existencia de reemplazos a la carne vacuna (por ejemplo, el carnero) a los que se recurría en caso de subas desproporcionadas de aquélla. Eso es lo 
Arroyo Abad et al. (2012), y para la construcción de índices de bienestar relativo (o welfare ratios) ${ }^{44}$. A lo que agregamos la expresión del salario en kilos de cereales y azúcar.

Los salarios reales, tanto en términos de BBB como medidos en kilos de alimentos básicos, eran en Santa Fe más altos que en otras varias localidades hispanoamericanas y aun europeas, aunque menores que en el norte de Europa y en los Estados Unidos ${ }^{45}$. Nada de esto es nuevo, aunque nuestros números son bastante menos «optimistas» que los de Arroyo Abad et al. Lo que sí muestran claramente, por el largo período de tiempo que abarcan, es la enorme volatilidad de los cálculos según el año que se tome (lo cual nos revela, una vez más, los límites de las comparaciones, a pesar de que siempre resulten atractivas). Es evidente que el período culminante de la guerra de fronteras (la década de 1730) implicó un aumento sustancial del costo laboral, medido en kilos de cereal. Pero, más allá de esto, la alta volatilidad de finales del siglo XVIII e inicios del siglo XIX parece mostrar también una progresiva pérdida del poder de compra de bienes de consumo básicos, lo cual se replica asimismo en otros lugares de Hispanoamérica. Pero debemos tener cuidado al respecto, ya que la evidencia es débil y contradictoria, y queda claro que no refleja la situación del espectro, cada vez más amplio, de bienes a disposición de los consumidores ${ }^{46}$. Tampoco, como hemos dicho, considera las posibilidades de reemplazo de muchos de esos bienes; y, valga repetirlo, los abundantes recursos aún vírgenes en esas áreas de frontera. En suma, a pesar de que sigue siendo bastante arriesgado afirmarlo, pareciera que en el tercer cuarto del siglo XVIII (período de descenso de precios y, como hemos dicho, de crecimiento económico) el poder adquisitivo del salario hubiera tendido a decrecer, a pesar de que esto no signifique, necesariamente, que empeorase el nivel de vida; sin embargo, a comienzos del siglo XIX ya había recuperado, y aun superado, los niveles anteriores, aunque es probable que por entonces fuese más importante la relación laboral como fuente de obtención de recursos, por el mismo aumento de las transacciones mercantiles. Eso permitiría a los trabajadores (mejor dicho: a

\footnotetext{
(footnote continued)

que hizo en 1794 Miguel Diez de Andino al ofrecer a sus peones carnero en vez de vacuno. AGPSF, Diez de Andino, Carpeta 1, leg. 18, f. 22.

44 Entendido como el salario ganado por el varón adulto dividido por los requerimientos mínimos de consumo de un individuo adulto promedio en un año dado. El resultado indica la cantidad de individuos que, teóricamente, podrían vivir de ese salario. Desde ya, esa ingesta mínima promedio de 2.000 calorías varía muchísimo en función de la edad, el sexo o las actividades del individuo. Floud et al. (2012, p. 46) muestran que en los niños puede llegar a ser sólo un 10\% de la de un adulto.

${ }^{45}$ Las de Potosí, Chile o México rondan los 300-500 g, mientras que las de Perú son aún mayores. El cálculo de Arroyo Abad et al. (2012) para Buenos Aires da un resultado bastante similar al nuestro, salvo para el período 1725-1774, en el que no vemos que se produzca la caída que muestra Arroyo Abad et al. (2012).

46 Por ejemplo, mientras el poder adquisitivo del salario se reduce en términos de maíz o azúcar, aumenta en trigo.
} 
CUADRO 1

ÍNDICES DE NIVEL DE VIDA DE LOS SALARIOS SANTAFESINOS, 1714-1808

\begin{tabular}{|c|c|c|c|c|c|}
\hline & & & \multicolumn{3}{|c|}{ Salario diario (en kg) } \\
\hline & BBB* & Welfare Ratio & Maíz & Trigo & Azúcar \\
\hline 1714 & 224,19 & 7,96 & 12,35 & 8,69 & \\
\hline 1715 & 224,19 & 7,96 & 12,35 & 8,69 & \\
\hline 1723 & 261,81 & 5,68 & 7,72 & 7,38 & 0,50 \\
\hline 1731 & 297,67 & 7,00 & 9,03 & 10,01 & 0,55 \\
\hline 1732 & 251,35 & 7,45 & 10,88 & 36,43 & 0,52 \\
\hline 1735 & 316,69 & 5,64 & 12,35 & 17,37 & 0,53 \\
\hline 1736 & 311,36 & 5,73 & 12,78 & 11,58 & 0,51 \\
\hline 1742 & 240,34 & 7,43 & 15,88 & 9,21 & 0,77 \\
\hline 1746 & 273,42 & 6,53 & 8,24 & 7,49 & 0,66 \\
\hline 1750 & 341,41 & 4,94 & 14,00 & 4,34 & \\
\hline 1756 & 336,28 & 5,31 & 12,35 & 5,79 & \\
\hline 1781 & 302,87 & 4,35 & 10,59 & 5,80 & 0,29 \\
\hline 1782 & & & 11,40 & 6,45 & 0,29 \\
\hline 1787 & & & & 8,27 & 0,64 \\
\hline 1794 & & & & 7,24 & \\
\hline 1796 & & & & 3,62 & \\
\hline 1800 & & & & 4,60 & \\
\hline 1802 & & & & 3,57 & \\
\hline 1805 & 276,84 & 8,41 & 16,47 & 11,58 & 0,68 \\
\hline 1806 & 334,57 & 6,96 & 7,06 & 6,49 & 0,91 \\
\hline 1807 & 368,94 & 4,99 & 7,28 & 4,07 & 0,48 \\
\hline 1808 & 253,81 & 6,30 & 9,06 & 11,58 & 0,52 \\
\hline
\end{tabular}

Fuentes: construido a partir de salarios y precios tomados de fuentes conventuales ya citadas, y de AGPSF, Colección Diez de Andino, Carpetas 9-56. Los datos figuran en el Apéndice on line.

Nota: * BBB: Barebone Basket. Costo medio de la BBB en gramos de plata, según el contenido intrínseco del numerario con los debasements que hemos mencionado anteriormente. 
sus familias, mediante el ingreso que le aportaban) hacer frente airosamente, por un tiempo, a las tormentas de la nueva centuria; aunque, de todos modos, eso todavía deberá ser materia de análisis mucho más integrales.

\section{CONCLUSIONES}

El caso santafesino, clave para la comprensión de la economía rioplatense durante el siglo XVIII, ha sido analizado aquí a partir de un cuerpo muy consistente de series de precios mayoristas. La historia de su movimiento secular permitió observar por primera vez lo acontecido durante un largo siglo en un área altamente estratégica en los circuitos de producción y comercialización regional, lo que permitió trascender los límites de los análisis disponibles, centrados en la ciudad de Buenos Aires, capital de fuerte impronta comercial y vinculada, desde siempre, al mundo atlántico: la única que hasta ahora poseía series de precios de esta longitud. Santa Fe nos muestra así una dinámica más representativa del movimiento interior de la economía colonial y permite comenzar a medir y comprender los procesos de convergencia e integración de ese vasto espacio.

Creemos así haber avanzado en la interpretación de la economía rioplatense en la época comprendida entre el final de la dura etapa de la conquista y los albores del comercio libre. Identificamos tres grandes momentos: el primero, que dura aproximadamente hasta 1730, en que entra en crisis el viejo asentamiento de la centuria anterior, basado todavía en el expolio de vastos recursos antiguos: mostrencos, como los extensos hatos de ganado cimarrón; o fruto de un todavía copioso trabajo indígena para una escasa población criolla, que se evidenciaba en la producción agrícola marcada aún por el relevante peso del maíz. En esa crisis, los bienes regionales, objeto de un importante comercio en una ciudad que era llave del intercambio, sufren una volatilidad considerable con tendencia a la baja, a la par que los locales registran el movimiento inverso, de la mano de una población estancada. Esa sociedad jerárquica sufría así los duros embates de la guerra de fronteras, saliendo de ella sólo cuando, al final de la década de 1740, lograron establecerse reducciones indígenas capaces de perdurar. Se abrió así otra etapa en la que ambas series, local y regional, tendieron a converger, iniciando, desde mediados del siglo, un recorrido descendente de larga duración. Ese fenómeno, paralelo a un probable aumento en la oferta monetaria y a un creciente valor relativo de la plata, respondió a un incremento en la productividad general de la economía dentro de su marco tradicional, es decir, sin cambio tecnológico. Ese crecimiento se potenció por varios sucesos, entre los cuales destaca la expansión sobre tierras de frontera, un leve pero constante aumento demográfico, la expulsión de los jesuitas y la desarticulación del vasto oligopolio comercial que había sostenido su esplendor, abriéndose así nuevas oportunidades mercantiles. Pero la destrucción de ese portentoso ente, sin embargo, parece haber sido un punto más en un recorrido 
iniciado antes: en efecto, ya desde mediados del siglo parece que la situación está cambiando, con ganancias de productividad impulsadas por fenómenos de expansión más estructurales: el aumento demográfico de las comunidades repartidas en tan vasto territorio, con la consiguiente acentuación de los intercambios y un uso más eficaz de los recursos; las mayores ganancias del comercio de intermediación, que fueron atrayendo a nuevos inmigrantes desde la Península. El tercer período comienza con la apertura atlántica: desde 1780, aun dentro del régimen colonial, su impacto en la economía fue concreto. Los precios de los bienes transables suben y se ven indicios de ganancias de productividad en los salarios.

El nivel de vida, a juzgar por el poder de compra del salario, varió enormemente a lo largo del tiempo, afectado entre otras cosas por coyunturas conflictivas, pero con tendencia al alza. Sin embargo, parece haber ido cediendo parte de su magnitud relativa al tiempo que los precios descendían y la economía se expandía durante el tercer cuarto del siglo XVIII. No contamos con datos del siguiente cuarto, pero a inicios de la centuria siguiente los coeficientes de bienestar han duplicado sus niveles de la década de 1780. Esa mejora, sin embargo, habría de sufrir pronto los embates de un nuevo ciclo inflacionario. De todos modos, parece haber garantizado durante bastante tiempo una base sólida al nivel de vida rioplatense, más alto que el de muchas economías comparables.

\section{FUENTES}

Archivo General de la Nación, ciudad de Buenos Aires, Argentina (AGN)

- Testimonios de remates de diezmos, Clase IV, 1618-1749, IX-13-3-2, expedientes de 1703, f. 8, y 1749, f. 10; íbid., 1750-1800, IX-13-3-3;

- Quadrante de Diezmos, IX-7-3-2 (para el período 1801-1810);

- Consulado de Buenos Aires, Santa Fe, Corrientes, t. IV, ff. 112 v.-113 r., IX-4-6-4.

Archivo General de la Orden de la Merced, ciudad de Córdoba, Argentina (AGOM)

- Libros de Gastos e Ingresos, n. ${ }^{\circ} 8,1780-1785 ; n^{\circ} 34,1706-1728 ;$ n. $^{\circ} 47$, 1753-1778; n. ${ }^{\circ} 48,1699-1718 ;$ n. $^{\circ} 59,1729-1752 ;$ n. $^{\circ} 64.1816-1819 ;$ n. $^{\circ}$ $66,1803-1816$.

Archivo General de la Provincia de Corrientes, ciudad de Corrientes, Argentina

- Fondo Censos, t. V. 
Archivo General de la Provincia de Santa Fe, ciudad de Santa Fe, Argentina (AGPSF)

- Libro de Entradas y Salidas del Colegio de la Compañía de Jesús de Santa Fe y sus dependencias, Fondo Contaduría, t. 6, años 1707-1748 y 1733-1749.

- Guías de Alcabalas, Fondo Contaduría, tt. 9-13, años 1783-1806.

- Cuentas particulares de Manuel Ignacio Diez de Andino, Colección Diez de Andino, Carpetas 9-68, años 1752-1807.

- Actas del Cabildo, tt. X, XI, XIV B, XV A y XVI A

- Remates de Diezmos, Fondo Contaduría, t. 7, años 1739-1766 y 17501766, leg. 1, f. 2 y t. 9, años 1774-1786, leg. 1.

Convento de San Francisco, ciudad de Santa Fe, Argentina (CSF)

- Libro de Gastos, 1755-1779, y 1804-1844;

- Libro de Ingresos, 1791-1844 y 1755-1791.

Departamento de Estudios Etnográficos y Coloniales, ciudad de Santa Fe, Argentina (DEEC-EC)

- Expedientes Civiles, t. 32, exp. 319, ff. 16 y ss.

\section{SUPPLEMENTARY MATERIAL}

To view supplementary material for this article, please visit http://dx.doi. org/10.1017/S0212610915000051

\section{BIBLIOGRAFÍA}

Acemoglu, D.; Johnson, S. y Robinson, J. (2002): «Reversal of Fortune: Geography and Institutions in the Making of the Modern World Income Distribution». Quarterly Journal of Economics 117 (4), pp. 1.231-1.294.

Aguirre, J. F. (1949-1950 [1793-1798]): «Diario del capitán de fragata de la Real Armada...», en Revista de la Biblioteca Nacional, Buenos Aires, tt. 18 y 19.

Allen, R.; Bassino, J. P., MA, D. y Van Zanden, J. (2005): «Wages, Prices, and Living Standards in China, Japan, and Europe, 1738-1925», en <http://www.nuff.ox.ac.uk/ users/allen/unpublished/ fiveauthorjehrev.pdf> .

Allen, R.; Murphy, T. y Schneider, E. (2012): «The Colonial Origins of the Divergence in the Americas: A Labor Market Approach». The Journal of Economic History 72 (4), pp. 863-894.

Alvarez, J. (1929): Temas de Historia Económica Argentina. Buenos Aires: El Ateneo.

Alves Carrara, A. (2008): "Para uma história dos preços do periodo colonial: questoês de método». Locus: revista de história 14 (1), Universidade Federal de Juiz de Fora, pp. 163-194. 
Arcondo, A. (1992): El ocaso de una sociedad estamental. Córdoba entre 1700 y 1760. Córdoba: Universidad Nacional de Córdoba.

Arroyo Abad, L., Davies, E. y Van Zanden, J. (2012): "Between Conquest and Independence: Real Wages and Demographic Change in Spanish America, 15301820». Explorations in Economic History 49 (2), pp. 149-166.

Assadourian, C. (1982): El sistema de la economía colonial. Mercado interno, regiones y espacio económico. Lima: Instituto de Estudios Peruanos.

Azara, F. DE (1809): Voyages dans l'Amérique Méridionale, par... Commissaire et Commandant des limites espagnoles dans le Paraguay depuis 1781 jusqu'en 1801 ... París: Dentu.

Azara, F. de (1873): Viajes inéditos... desde Santa-Fé á la Asuncion. Buenos Aires: Imprenta y librería de Mayo.

Banzato, G. (2005): La expansión de la frontera bonaerense. Posesión y propiedad de la tierra en Chascomús, Ranchos y Monte, 1780-1880. Bernal: Editorial Universidad Nacional de Quilmes.

BARBA, F. (1999): Aproximación al estudio de los precios y salarios en Buenos Aires desde fines del siglo XVIII hasta 1860. La Plata: Editorial de la Universidad de La Plata.

Barriera, D. (2006): Nueva Historia de Santa Fe. Economía y Sociedad (siglos XVI a $X V I I I)$ vol. 3 Rosario: Prohistoria.

BARRIERA, D. (2013): Abrir puertas a la tierra. Microanálisis de la construcción de un espacio político. Santa Fe, 1573-1640. Santa Fe: Museo Histórico Provincial.

Besio Moreno, N. (1939): Buenos Aires puerto del Río de la Plata, capital de la Argentina. Estudio crítico de su población. 1536-1936. Buenos Aires, Tuduri.

Broadberry, S. y Gupta, B. (2005): «The Early Modern great Divergence: Wages, Prices and Economic Development in Europe and Asia, 1500-1800». CEPR Discussion Papers (4.947). London: Centre for Economic Policy Research. En <http://elsa. berkeley.edu/users/webfac/olney/e211_fa03/e211-gupta.pdf $>$.

BRoIDE, J. (1951): «La evolución de los precios pecuarios argentinos en el período 18301850». Revista de la Facultad de Ciencias Económicas 32 (4), Universidad de Buenos Aires, pp. 1-72.

BRown, K. (1992): «Price movements in eighteenth-century Peru-Arequipa». en E. Tandeter y L. Johnson, Economías coloniales. Precios y salarios en América Latina en el siglo XVIII. Buenos Aires: Fondo de Cultura Económica, Buenos Aires, pp. 173-200.

Burzio, H. (1958): Diccionario de la moneda hispanoamericana. Santiago de Chile: Fondo Histórico y Bibliográfico José Toribio Medina.

Burzio, H. (ed.) (1971): Manifiesto de la plata extraída del cerro de Potosí (1556-1800). Buenos Aires: Academia Nacional de la Historia.

Cervera, M. (1907): Historia de la ciudad y provincia de Santa Fe. Santa Fe: La Unión.

Coatsworth, J. (1990): Los orígenes del atraso. México: Alianza.

CoRTÉs Conde, R. (1979): El progreso argentino 1880-1914. Buenos Aires: Sudamericana.

Cuesta, M. (2009): Precios, población, impuestos y producción. La economía de Buenos Aires en el siglo XVIII. Buenos Aires: Temas.

DJENDEREDJIAN, J. (1997-1998): «Una reevaluación del peonaje por deudas. El caso de la producción yerbatera paraguaya a inicios del siglo XIX». Boletín del Instituto de Historia Argentina y Americana "Dr. Emilio Ravignani». 3. serie 16-17, pp. 85-122.

DJENDEREDJIAN, J. (2006): «Estrategias de captación y fidelización de clientes en un medio competitivo. Crédito, moneda y comercio rural en el sur entrerriano a fines de la colonia». Anuario IEHS 21, pp. 287-310.

DJENDEREDJIAN, J. (2008): La agricultura pampeana en la primera mitad del siglo XIX. Buenos Aires: Siglo XXI. 
Djenderedjian, J. y Martiren, J. L. (2013): «Los precios de los bienes en las fronteras bravías del Río de la Plata colonial: Santa Fe durante la primera mitad del siglo XVIII». América Latina en la Historia Económica 20 (2), pp. 33-66.

Dobado, R. (2010): «Prices and Wages in Bourbon Mexico from an international comparative perspective», en J. Morilla, J. Hernández Andreu, J. L. García Ruiz, y J. M. Ortiz-Villajos (eds.), Homenaje a Gabriel Tortella. Las claves del desarrollo económico y social. Madrid: LID y Universidad de Alcalá.

Dobado, R. y García, H. (2014): "Neither So Low Nor So Short: Wages and Heights in Bourbon Spanish America from an International Comparative Perspective». Journal of Latin American Studies 46 (2), pp. 291-321.

Dobado-GonzÁlez, R. (2015): «Pre-Independence Spanish Americans: Poor, short and unequal... or the Opposite?». Revista de Historia Económica / Journal of Iberian and Latin American Economic History, doi:10.1017/S0212610914000135, Published online by Cambridge University Press 12 January 2015.

FISHER, D. (1996): The Great Wave. Price Revolutions and the Rhythm of History. Oxford: Oxford University Press.

Floud, R. et al. (2012): The Changing Body. Health, Nutrition, and Human Development in the Western World since 1700. Cambridge: Cambridge University Press.

Friedman, M. y Schwartz, A. (1963): A Monetary History of the United States, 1867-1960. Princeton: Princeton University Press.

Ganson, B. (2003): The Guarani under Spanish Rule in the Rio de la Plata. Stanford: Stanford University Press.

Garavaglia, J. C. (1995): «Precios de los productos rurales y precios de la tierra en la campaña de Buenos Aires: 1750-1826». Boletín del Instituto de Historia Argentina y Americana "Dr. Emilio Ravignani». 3. serie 11, pp. 65-112.

Garavaglia, J. C. (1999): Pastores y labradores de Buenos Aires: una historia agraria de la campaña bonaerense 1700-1830. Buenos Aires: Ediciones de la Flor.

González Mariscal, M. (2013): Población, coste de la vida, producción agraria y renta de la tierra en Andalucía Occidental, 1521-1800. Tesis doctoral. Madrid: Universidad Complutense de Madrid.

Gorostegui, H. (1962-1963): «Los precios del trigo en Buenos Aires durante el gobierno de Rosas». Anuario del Instituto de Investigaciones Históricas 6, Rosario, pp. 141-155.

HABER, S. (1998): "Introduction: Economic growth and Latin American Economic Historiography», en S. Haber, How Latin America fell behind: Essays on the Economic Histories of Brazil and Mexico, 1800-1914. Stanford: Stanford University Press.

Hoffman, P. H.; Jacks, D., Levin, P. y Lindert, P. (2002): «Real Inequality in Europe since 1500». The Journal of Economic History 62, The Economic History Association, pp. 322-355.

HalPerin Donghi, T. (1979): Revolución y guerra. Formación de una élite dirigente en la Argentina criolla 2.a ed. México: Siglo XXI.

JoHNSON, Harold (1973): «A preliminary inquiry into money, prices, and wages in Rio de Janeiro, 1763-1823», en D. Alden (ed.), Colonial roots of modern Brazil. Berkeley: University of California Press.

Johnson, L. (1990): «Salarios, precios y costo de vida en el Buenos Aires colonial tardío». Boletín del Instituto de Historia Argentina y Americana "Dr. Emilio Ravignani». 3. serie, 2, pp. 133-157.

Johnson, L. (1992): «La historia de precios de Buenos Aires durante el período virreinal», en L. Johnson, y E. Tandeter (comps.), Economías coloniales. Precios y salarios en América Latina, siglo XVIII. Buenos Aires: Fondo de Cultura Económica. 
Larrain Melo, J. (1980): «Movimiento de precios en Santiago de Chile, 1749-1808. Una interpretación metodológica». Jahrbuch für Geschichte von Staat, Wirtschaft und Gesellschaft Lateinamerikas 17, pp. 199-259.

Llopis, E. y García, H. (2007): "Cost of living and wages in Madrid, 1680-1800». The Seventh European Historical Economics Society Conference, 29 junio-1 julio de 2007, Lund, Suecia.

MAEDER, E. (1976): «La población del litoral argentino según la breve relación geográfica y política de la gobernación del Río de la Plata (1760)». Folia Histórica 2, Resistencia, pp. 129-176.

Malanima, P. (2006): «An Age of Decline. Product and Income in Eighteenth-Nineteenth Century Italy». Rivista di Storia Economica XXII (1), pp. 91-133.

Matтoso, K. (1973): «Os preços na Bahia de 1750 a 1930». Colloques Internationaux du Centre National de la Recherche Scientifique. París: Éditions du CNRS, pp. 167-82.

Mayo, C. (dir.) (2000): Pulperos y pulperías de Buenos Aires (1740-1830). Buenos Aires: Biblos.

Miguez, E. (2008): Historia económica de la Argentina. De la Conquista a la crisis de 1930. Buenos Aires: Sudamericana.

Moutoukias, Z. (2000): «Gobierno y sociedad en el Tucumán y el Río de la Plata, 1550-1800», en E. Tandeter (dir.), Nueva Historia Argentina. t. 2. Buenos Aires: Sudamericana.

Gallo, A. y Newland, C. (2004): "Globalización y convergencia de precios en el imperio español, 1660-1810». Revista de Historia Económica 22 (3), pp. 573-596.

Hoffman, P. (2000): Growth in a Traditional Society: The French Countryside, 1450-1815. Princeton: Princeton University Press.

Nordhaus, W. (1996): «Do Real-Output and Real-Wage Measures Capture Reality? The History of Lighting Suggests Not», en T. Bresnahan y R. Gordon (eds.), The Economics of New Goods. Chicago: University of Chicago Press.

Novara, J. y Palmieri, H. (1968): Contribución a la historia de los precios en Córdoba, 1887-1907. Córdoba: Universidad Nacional de Córdoba.

Özmucur, S. y PamuK, S. (2002): «Real Wages and Standards of Living in the Ottoman Empire, 1489-1914». Journal of Economic History 2, pp. 293-321.

Paucke, F. (1942-1944): Hacia allá y para acá. Una estada entre los indios mocobíes, 1749-1767. Tucumán-Buenos Aires: Universidad Nacional de Tucumán.

Prados De La Escosura, L. (2004): «When did Latin America fell behind? Evidence from long-run International Inequality». Working Paper 04-66, Economic History and Institutions Series 04. Madrid: Universidad Carlos III.

RoBertson, J. y G. (1920): La Argentina en la época de la revolución. Buenos Aires: Vaccaro.

Romano, R. (1998): Moneda, seudomonedas y circulación monetaria en las economías de México. México: FCE.

Roverano, A. (1963): «La despoblación de Santa Fe (1713-1730)». Revista de la Junta Provincial de Estudios Históricos 27, Santa Fe, pp. 7-27.

SusNIK, B. (1990-1991): Una visión socio-antropológica del Paraguay del siglo XVIII. Asunción: Museo Etnográfico «Andrés Barbero».

TANDETER, E. y WaChtel, N. (1992): «Precios y producción agraria en Charcas en el siglo XVIII", en e. Tandeter y L. Johnson, Economías coloniales. Precios y salarios en América Latina en el siglo XVIII. Buenos Aires: Fondo de Cultura Económica, Buenos Aires, pp. 221-301.

TARRAGÓ, G. (1995-1996): «Santa Fe en el período tardo-colonial: producción ganadera, estancias y regiones». Anuario 17, Segunda Época, Escuela de Historia, Facultad de Humanidades y Artes, Universidad Nacional de Rosario, pp. 217-238. 
Telesca, I. (2009): Tras los Expulsos. Cambios demográficos y territoriales en el Paraguay después de la expulsión de los jesuitas. Asunción: Universidad Católica.

Tognetti, L. (2008): «La compraventa y los precios de la tierra en el sur de Córdoba, 1860-1880», en XXI Jornadas de Historia Económica. Asociación Argentina de Historia Económica / Universidad Nacional de Tres de Febrero: Caseros.

ToRres, J. (2013): «Precios, oferta monetaria y crecimiento económico en la Nueva Granada de la segunda mitad del siglo XVIII». Revista de Economía Institucional 29, pp. 195-225.

VAN Zanden, J. L. (1999): "Wages and the standard of living in Europe, 1500-1800». European Review of Economic History 2, pp. 175-197.

VAN ZANDEN, J. L. (2005): "What Happened to the Standard of Living Before the Industrial Revolution? New Evidence from the Western Part of the Netherlands», en R. Allen, T. Bengtsson, y M. Dribe (eds.), Living Standards in the Past. New Perspectives on Well-being in Asia and Europe. Oxford: Oxford University Press.

VRIES, J. DE (1993): «Between Purchasing Power and the World of Goods: understanding the household economy in early modern Europe», en J. Brewer y R. Porter (eds.), Consumption and the World of Goods. London: Routledge.

WILDE, G. (2009): Religión y poder en las misiones de guaranies. Buenos Aires: SB. 